\title{
MEASUREMENT OF SODIUM WORTH IN THE ENRICO FERMI REACTOR
}

\author{
B. M. Segal \\ R. E. Horne
}




\section{DISCLAIMER}

This report was prepared as an account of work sponsored by an agency of the United States Government. Neither the United States Government nor any agency Thereof, nor any of their employees, makes any warranty, express or implied, or assumes any legal liability or responsibility for the accuracy, completeness, or usefulness of any information, apparatus, product, or process disclosed, or represents that its use would not infringe privately owned rights. Reference herein to any specific commercial product, process, or service by trade name, trademark, manufacturer, or otherwise does not necessarily constitute or imply its endorsement, recommendation, or favoring by the United States Government or any agency thereof. The views and opinions of authors expressed herein do not necessarily state or reflect those of the United States Government or any agency thereof. 


\section{DISCLAIMER}

Portions of this document may be illegible in electronic image products. Images are produced from the best available original document. 


\section{FOREWOR D}

This report is one of a series of reports on the low-power (up to $1 \mathrm{Mwt}$ ) and high-power (up to $200 \mathrm{Mwt}$ ) nuclear testing of the Enrico Fermi fast breeder reactor. The Nuclear Test Program is planned, directed, and evaluated by Atomic Power Development Associates, Inc. (APDA). The Tests are conducted by Power Reactor Development Company (PRDC). The reactor proper is owned and operated by PRDC. The steam generators and electrical generation facilities are owned by The Detroit Edis on Company (DECo).

Many people have contributed to the success of the nuclear testing of the Fermi reactor. Iisted below are the names of those people, exclusive of the authors, who made a significant contribution to some phase of the work reported in this document.

$\underline{\text { APDA }}$

C. E. Branyan

R. E. Mueller

J. B. Nims

H. A. Wilber

\section{$\underline{\text { PR DC }}$}

E. I. Alexanderson

D. A. Erdman
DECo

D. F. Gasvoda 
LIST OF ILLUSTRA TIONS . . . . . . . . . . . . . . . . . . . 4

LIST OF TABLES . . . . . . . . . . . . . . . . . . . . . . 4 4

SUMMARY . . . . . . . . . . . . . . . . . . . . . . 5

I. PURPOSE OF TEST . . . . . . . . . . . . . . . . . 6

II. DESCRIPTION OF THE ENRICO FERMI REACTOR . . . . . . . 7

A. GENERAL DESCRIPTION . . . . . . . . . . . . . . . . . . . 7

B. DESCRIPTION OF THE SPECIAL CORE SUBASSEMBLIES . 10

1. Normal Core A Subas sembly . . . . . . . . . . . . 10

2. Special Sodium Worth Subassembly .......... 11

III. EXPERIMENTAL PROCEDURE . . . . . . . . . . . . . . 13

A. DESCRIPTION OF TEST ................. 13

1. Step Definitions . . . . . . . . . . . . . . . . 13

2. Steps Performed ................... 13

3. Reactivity Measurements ............... 14

B. REACTOR PLANT CONDITIONS . . . . . . . . . . . . . . 16

C. NEUTRON SOUR CE AND INSTRUMENTATION . . . . . . . . 17

1. Neutron Source . . . . . . . . . . . . . . 17

2. Instrumentation ................. 18

IV. EXPERIMENTAL RESULTS AND ANALYSIS . . . . . . . . . . 20

A. REACTIVITIES MEASURED . . . . . . . . . . . . 20

1. Measured Results . . . . . . . . . . . . . . 20

2. Probable Errors in Measurements........... 20

B. METHOD OF ANALYSIS . . . . . . . . . . . . . . . 22

1. Preservation of Small Reactivity Differences . . . . . 22

2. Interpolation for Missing Flooded Steps . . . . . . . 23

3. Estimate of Reactivity Uncertainty after Reloading . . . 23

C. DATA REDUCTION . . . . . . . . . . . . . . . . . 23

1. Reference Steps and Reloading Uncertainty . . . . . . 24

2. Voided Steps... . . . . . . . . . . . . . . 26

3. Flooded Steps and Missing Flooded Steps . . . . . . 28

4. Determination of Sodium Worth. . . . . . . . . . . 30

5. Effect of Bunching Voided Subassemblies . . . . . . 30

V. SODIUM WORTH PREDICTIONS . . . . . . . . . . . . . . . 33

A. ZPR-III PREDICTION . . . . . . . . . . . . . . . . . 33

B. MULTIGROUP DIFFUSION THEORY PREDICTION. . . . . . 35

Vi. CONCLUSIONS ...................... . . 38 


\section{LIST OF ILLUSTRATIONS}

Figure

Perspective View of Reactor . . . . . . . . . . 8

Reactor Cross Section. . . . . . . . . . . . . . . .

Core A Subassembly Showing Modifications for Sodium

\section{LIST OF TABLES}

Table

I

I I

III

IV

IV. A

IV.B

$\mathrm{V}$

VI

VII

VIII

IX $\underline{\text { Page }}$

Average Core Radius of Step Substitutions . . . . . . . 14

Basic Reactivities Measured . . . . . . . . . . . 21

Slope of Regulating Rod Calibration Curve . . . . . . . . 24

Reference Reactivities Relative to Five Standard Regulating Rod Positions . . . . . . . . . . . . 25

Reference Intercomparison Relative to Step R2 . . . . . 25

Reference Intercomparison Relative to Step R3 . . . . . 25

Voided Steps Compared to Reference Step R3 . . . . . . . . 27

Flooded Steps F1, F4, F6 Compared to Reference

Step R3 . . . . . . . . . . . . . . . . . . 29

Estimated Missing Flooded Steps Compared with

Reference Step R3 . . . . . . . . . . . . . . . . .

Determination of Sodium Worth . . . . . . . . . . 32

ZPR-II Sodium Worth Predictions . . . . . . . . . . 34 


\section{SUMMARY}

In this test, performed between November 18 and December 10 , 1963, the reactivity worth of the sodium in a core subassembly was measured as a function of the subassembly radial position in the core lattice. A specially designed type of core subassembly, in which the core section was able to be either completely voided of sodium or filled normally, was used in the test. The axially averaged (or columnar) core worth of sodium was obtained at seven core radii by measuring the reactivity of seven pairs of core loadings, each pair containing four of the special subassemblies in separated locations at equal radii from the core center. The special subassemblies were voided of sodium in the first loading of each pair and filled for the second; four subassemblies were used together to insure that an adequate reactivity difference would be observed between the voided and flooded loadings at each of the seven core radii studied. This reactivity difference obtained at each radius allowed the columnar core sodium worth to be evaluated at that radius. The effect of "bunching" the four special subassemblies into adjacent rather than separated locations was investigated also.

The observed columnar core worth of sodium was positive throughout the lattice, varying from a minimum value of 1.82 cents per kilogram (cents $/ \mathrm{kg}$ ) for a column near the center, to a maximum of 2.19 cents $/ \mathrm{kg}$ near the edge, with a value of 2.01 cents $/ \mathrm{kg}$ for an average column. These results have probable errors of less than \pm 5 per cent. The existence of negative sodium temperature and void coefficient of reactivity is thus confirmed.

The measured values agree quite well with those predicted by multigroup diffusion theory. The average column value of 2.01 cents $/ \mathrm{kg}$ is also in good agreement with the value for total core sodium worth of $\sim 1.9$ cents $/ \mathrm{kg}$ estimated from the ZPR-III Fermi Critical Experiment. 


\section{PURPOSE OF TEST}

The worth of the sodium in the Enrico Fermi reactor was measured to obtain more exact values than were possible in the ZPR-III critical experiment ${ }^{1}$ and, in particular, to study the spatial distribution of the worth in more detail. Knowledge of the distributed sodium worth is important for improving the predicted values of the sodium temperature and power coefficients of reactivity. Both of these coefficients, together with the sodium void coefficient, preferably should be negative in a fast reactor, because they are assets to the reactor stability and safety. Negative values were predicted for these coefficients for the Enrico Fermi reactor design; the ZPR - III experiment and the present test provide confirmation of this aspect of the design. An approximate check of the actual value of the average sodium worth of the core, obtained from the ZPR-III experiment, was obtained from this test; this value had been open to doubt due to the need for substituting aluminum for much of the sodium in the critical experiment.

Measurements of the distributed sodium worth are also very valuable because they provide detailed checks on worth calculations. In the Enrico Fermi core they are of particular importance because in a core of this size (about 400 liters volume), the dominant mechanism by which sodium losses affect reactivity is by increased neutron leakage from the core. In a larger core (approaching 1000 liters and above) such isolated study of this "leakage component" would be impossible, although the component remains a major contributor to the total sodium worth. 


\section{DESCRIPTION OF THE ENRICO FERMI REACTOR}

\section{A. GENERAL DESCRIPTION}

The Enrico Fermi reactor and its associated structures are shown in perspective in Figure 1. The reactor is contained in a stainless steel reactor vessel sealed at the top by a rotating shield plug which supports the control mechanisms, the holddown mechanism, and the fuel handling mechanism. The reactor vessel is surrounded by borated and plain graphite neutron shielding material which is contained inside the primary shield tank. The reactor is of the fast breeder type, cooled by sodium, and operated at essentially atmospheric pressure. The maximum reactor power with the first core loading (Core A) is $200 \mathrm{Mwt}$.

The core and blanket, located in the lower reactor vessel, consist of square subassemblies containing the fuel pins and blanket rods arranged to approximate a cylinder about 80 inches in diameter and 70 inches high. The core, contained in the central portion of the core subassemblies, approximates a right cylinder 31 inches in diameter and 31 inches high; it is axially and radially surrounded by breeder blankets. The fuel in Core A consists of zirconium-clad pins containing U-10 w/o molybdenum alloy with the uranium enriched to $25.6 \mathrm{w} / \mathrm{O} \mathrm{U}-235$. Each fuel subassembly in the core contains 140 fuel pins for a total mass of approximately 4.75 kilograms of U-235 per subassembly. The blanket is depleted U-3 w/o molybdonum alloy.

The reactor cross section, shown in Figure 2, indicates the placement of individual components within the lower reactor vessel. There is a total of 149 central lattice positions occupied by core and inner radial blanket subassemblies, the neutron source, and the 10 operating control and safety rod channels. All these positions are supplied with sodium coolant flowing upward from a high-pressure plenum which is connected to the discharge lines of the three primary sodium pumps. The coolant flows upward through the individual core and inner radial blanket subassemblies into a large upper plenum and from there by gravity to the three intermediate heat exchangers and then to the suction side of the primary pumps. Sodium also is used in the secondary cooling system.

Lattice positions surrounding the inner radial blanket comprise the outer blanket area and, when filled with outer radial blanket subassemblies, form an annular region whose top and bottom are at the same elevation as the top and bottom of the inner radial blanket. Surrounding the outer radial blanket are lattice positions used for stainless steel subassemblies that provide thermal and neutron shielding. The outer radial blanket and shielding lattice positions are supplied with sodium coolant from the lowpressure plenum. The sodium from the low-pressure plenum, after cooling the blanket and thermal shield subassemblies, is mixed in the upper plenum with the sodium from the core before flowing to the intermediate heat exchangers. 


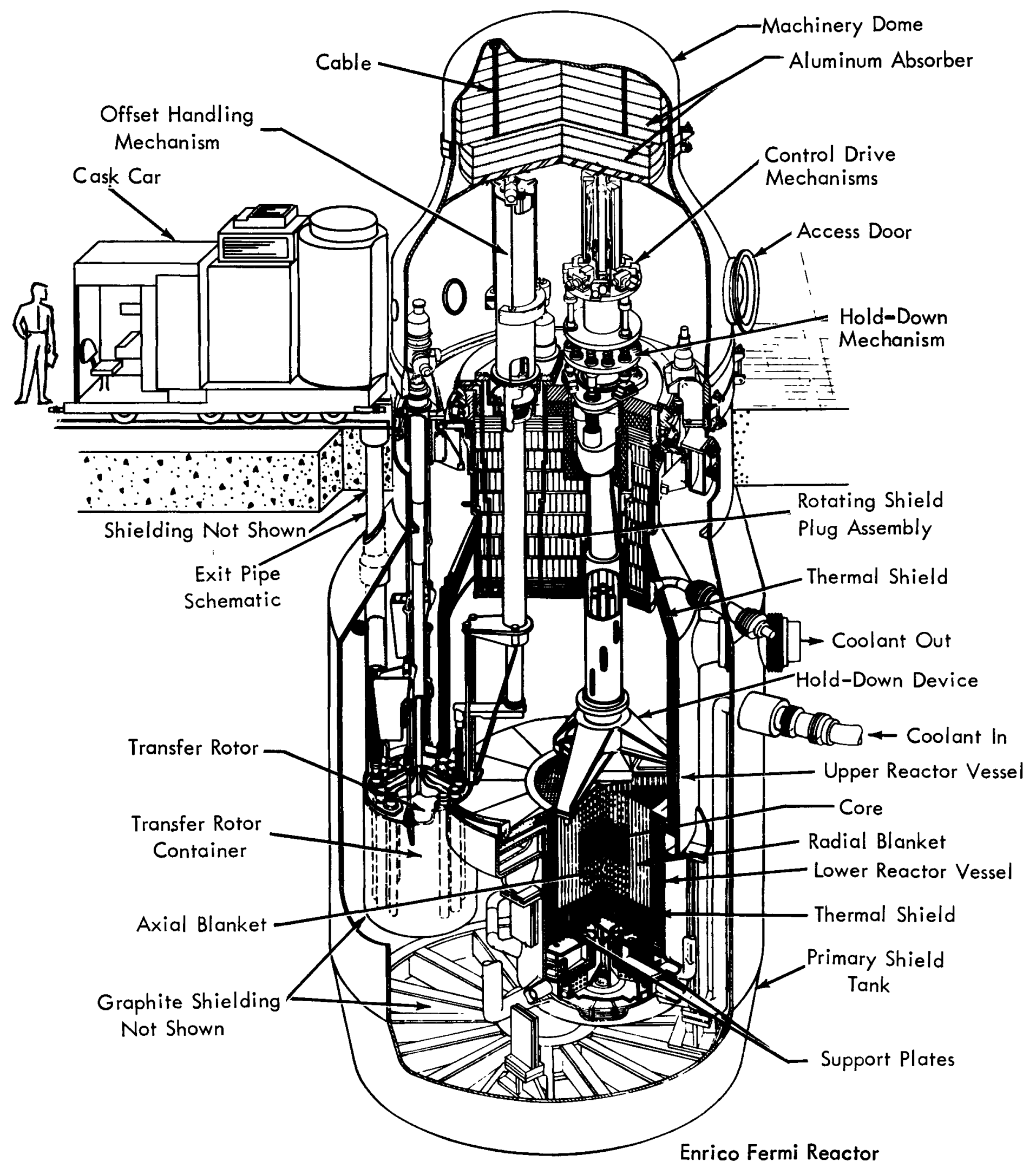

FIG. 1 PERSPECTIVE VIEW OF REACTOR 


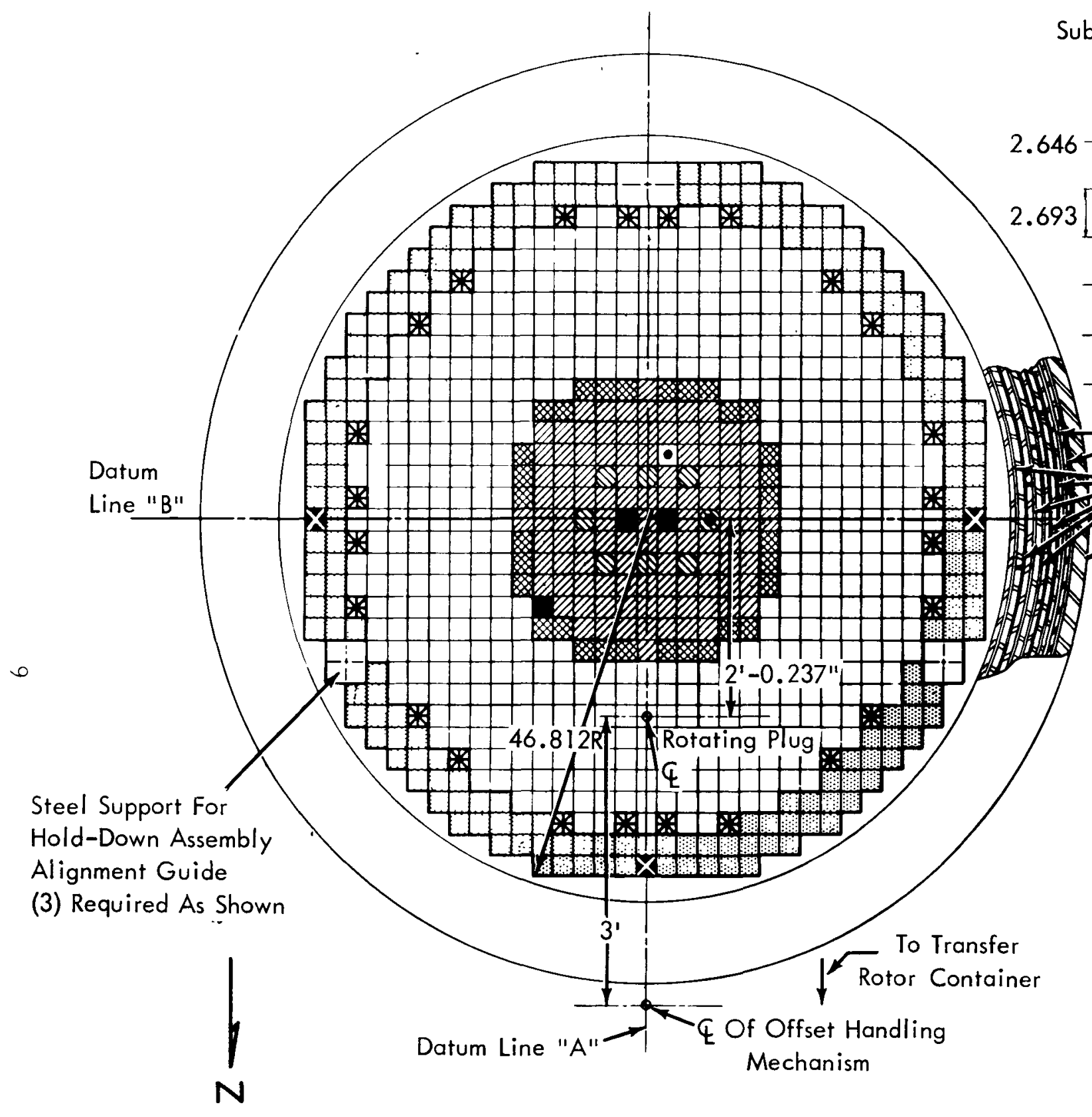

Subassembly Clearance

Arrangement

$\begin{array}{ll}2.693 & 0.047\end{array}$

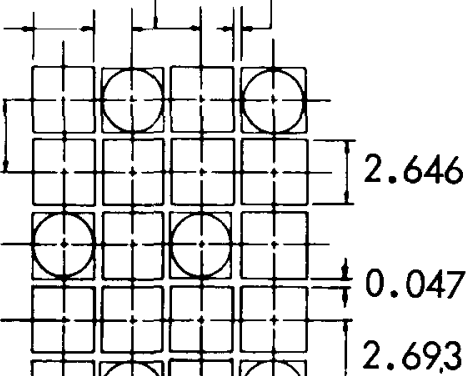

Thermal Baffles

Thermal Shield Installed

In Segments

Vessel

DESCRIPTION

QUANTITY

Q Safety Rod................. 8

Core Subassemblies ......... 105

Inner Radial Blanket

- Subassemblies............ 32

Outer Radial Blanket

Subassemblies. . . . . . . . . . . 499

Possible Storage for Core

$\otimes$ or Inner Radial Blanket

Subassemblies............ 24

Thermal Shield in

Form of Steel Rods ... . . . . . . 195

Thermal Shielding in Form

X of Steel Rods Used for

Surveillance Tubes. . . . . . . . . 3

- Neutron Source LocationNO5NO4 . 1

- Surveillance Subassembly

- Location POI PO3...........

Total Subassemblies. . . . . . . $\overline{870}$

Oscillator Rod Temporary

Location PO3POO

The Position Under the Center of the

Rotating Plug is Vacant. 
The reactor is controlled by two operating control rods and seven safety rods; provisions have been included in the design for an eighth safety rod. The rods are of the poison type, containing bor on carbide $\left(\mathrm{B}_{4} \mathrm{C}\right)$ in which the bor on is enriched in boron-10 (B-10). One operating control rod is for regulating purposes and the other for shimming. Both rods have approximate reactivity worths of 46 cents. The seven safety rods, which are spaced around the center of the core, provide shutdown reactivity. During operation of the reactor, the safety rods are held just above the axial blanket section of the core so that they can be rapidly inserted into the core if a scram becomes necessary. Each of the safety rods has a reactivity worth in excess of $\$ 1.00$. The movements of the control and safety rods are actuated from the top. During fuel reloading, they are delatched from their drive extensions to allow them to remain in the core.

The neutron detectors (fission and ion chambers) for normal reactor operation at power are located in 6 neutron-counter tubes (NCT) embedded in the graphite neutron shield surrounding the reactor vessel. There are 11 channels of nuclear instrumentation distributed throughout the 6 neutron-counter tubes in a manner that will cover the full power range during operation.

An antimony-beryllium ( $\mathrm{Sb}-\mathrm{Be}$ ) neutron source is located in the reactor at the core-blanket interface (Figure 2) to provide a neutron flux at the neutron detectors during reactor startup and to maintain a flux when the reactor is shut down. The radioactive antimony portion of the source is made as a separate piece for easy replacement and is in the form of a rod approximately 0.7 inch in diameter and 25 inches long. The radioantimony rod fits inside a beryllium assembly which is in the form of a hollow cylinder inside a stainless steel can having the external dimensions of a normal core subassembly fuel can.

Additional information concerning the reactor design may be found in the Enrico Fermi Hazards Summary Report. 2

\section{B. DESCRIPTION OF THE SPECIAL CORE SUBASSEMBLIES}

Four identical special core subassemblies were designed and manufactured for the purpose of measuring sodium worth in the Enrico Fermi reactor; the comparis on with a normally designed Core A subassembly is given in the following paragraphs.

\section{Normal Core A Subassembly}

A normal Core A fuel subassembly is composed of the upper axial blanket, the fuel, and the lower axial blanket. Between the upper and lower axial blanket sections and the core section there are gaps of 3 inches and 1.5 inches, respectively. 


\section{Special Sodium Worth Subassembly}

The four special subassemblies, illustrated in Figure 3, differed in two respects from a normal Core A subassembly; first, the axial blanket pins were omitted from both the upper and lower axial blanket sections. This was a manufacturing economy, judged to have a negligible influence on the accuracy of the sodium worth measurements. Secondly, to allow the core section to be either voided or filled normally with sodium, stainless steel bulkheads were placed immediately above and below the core region. The bulkheads were constructed so that they could be mechanically penetrated after removal of the subassembly from the reactor. Before penetration. the core section would be voided of sodium; after penetration and following reinsertion of the subassembly into the reactor, the core section would fill normally. Figure 3 shows the modifications required to convert a normal into a special subas sembly.

The free volume in the core region of the sodium worth subassemblies was determined using a displacement gas pressure method ${ }^{3}$ in which the void region of the subassembly was connected to a system of known volume. A gas in this volume, at a known pressure, was expanded into the evacuated free volume of the sodium worth subassembly. The resulting pressure was measured and the gas laws used to compute the unknown volume in the subassembly. Repeated measurements on the same subassembly indicated a $2 \sigma$ uncertainty ( 95 per cent confidence level) of $\pm 0.86 \mathrm{cc}$ on the measured volume. The values obtained for the void volume of the four subassemblies were 1902.31, 1901.87, 1902.45 and 1901.34 cubic centimeters, respectively. The total void volume of the four special subassemblies is therefore $7607.97 \pm 2.96$ cubic centimeters, corresponding to a total sodium content of 6.756 kilograms, with an uncertainty due to the volume measurements of less than \pm 0.04 per cent. This does not account for possible error in the value of $0.88 \overline{8}$ grams per cubic centimeter assumed for the density of sodium at $517 \mathrm{~F}$. 

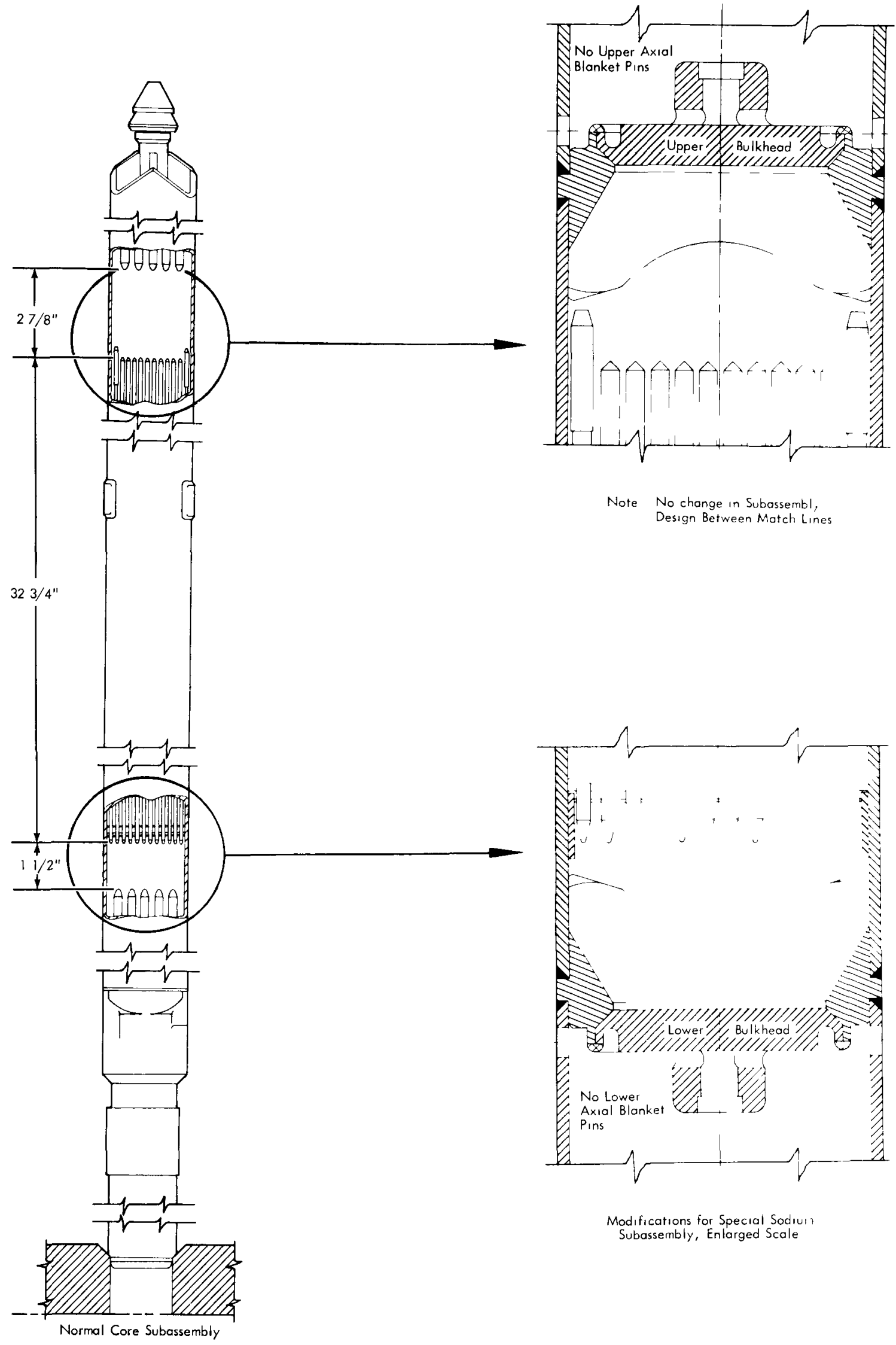

Note No change in Subossembl, Design Between Match Lines

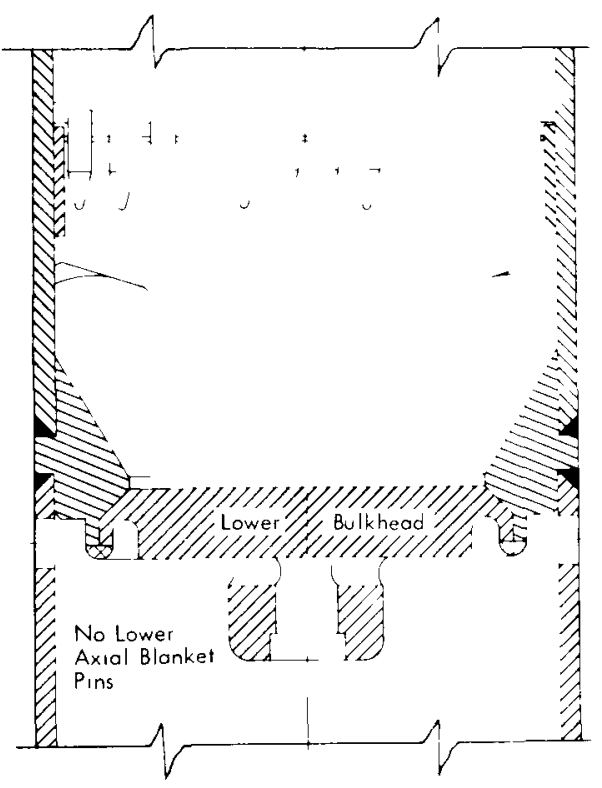

Modifications for Special Sodiui? Subassembly, Enlarged Scale

FIG. 3 CORE SUBASSEMBLY SHOWING MODIFICATIONS FOR A SODUIM WORTH SUBASSEMBLY 


\section{EXPERIMENTAI PROCEDURE}

\section{A. DESCRIPTION OF TEST}

The test procedure was carried out in accordance with a written, preplanned program 4 and consisted of measuring the reactivity of a series of reactor loadings; each complete loading is referred to as a "step" in the procedure. There were three types of steps as defined below.

\section{Step Definition}

Reference Steps - Loadings where all the core subassemblies were normal.

Voided Steps - Loadings where the four special subassemblies in the voided state had been substituted for four normal core subas semblies.

Flooded Steps - Loadings where the four special subassemblies in the flooded state had been substituted for four normal core subas semblies.

\section{Steps Performed}

Sixteen steps, numbered chronologically 1 through 16 , were performed during the test. These steps were:

Reference Steps - Five (5) reference steps, chronologically Steps 1, 6, 11, 12 and 16, were renumbered R 1 through R5, respectively, for the purpose of analysis. The purpose of returning so frequently to the reference configuration was twofold: (1) to check for any possible long-term reactivity drift due to a phase change in the uranium alloy fuel or some other unknown effect, and (2) to statistically study the small random reactivity uncertainties associated with holddown movements and subassembly angular reorientation following reloading.

Voided Steps - Eight (8) voided steps, chronologically Steps 2 through 5 and 7 through 10 , respectively, were numbered V1 through V8 for analysis. For all these steps except V8, the four special subassemblies in the voided state were substituted for normal subassemblies, one in each core quadrant at a fixed core radius for each step. For Step V8, the four voided subassemblies were loaded in a "bunch" of four adjacent locations, all in a single core quadrant. Separate voided measurements at these "bunched" locations had been 
made previously in Steps V2, V5, and V7; thus an estimate could be made of any reactivity effect of bunching voided subass emblies.

Flooded Steps - Three (3) flooded steps, chronologically Steps 13 through 15 , respectively, were numbered Fl, F4, and F6 for analysis. These steps were performed after all the voided steps were completed. The special subassemblies were removed from the reactor, cleaned, and their upper and lower steel bulkheads penetrated, allowing the core region to fill normally with sodium after the subassemblies were reloaded into the reactor. The four special subassemblies in the flooded state were substituted for four normal subassemblies, as was done for the voided steps; the substitutions made in flooded Steps F1, F4, and F6 were at the same locations as voided Steps V1, V4, and V6, respectively. To economize on reactor time, flooded measurements were not made on every measured void configuration. Instead, results for the four omitted flooded steps (corresponding to the voided Steps V2, V3, V5, and V7) were estimated by interpolation during the analysis.

The core locations involved in the substitutions during the voided and flooded steps are illustrated in Figure 4. The average core radius at which the substitutions occurred in each step is given in Table $I$.

TAB LE I

AVERAGE CORE RADIUS OF STEP SUBSTITUTIONS

Step Number

$\mathrm{Vl}, \mathrm{Fl}$

$\mathrm{V} 2$

V3

$\mathrm{V} 4, \mathrm{~F} 4$

V5

$\mathrm{V} 6, \mathrm{~F} 6$

$\mathrm{V} 7$

V8
Average Core Radius, $\mathrm{cm}$

39.9

34.2

15.3

9.7

29.1

21.6

38.7

33.9 (bunch)

\section{Reactivity Measurements}

During each substitution step, the reactivity state of the reactor was measured several times by reading the critical regulating rod position (CRRP) and the positive period ( $P P$ ) at a number of noncritical regulating rod positions. While making these measurements, the shim control rod was fully inserted. 


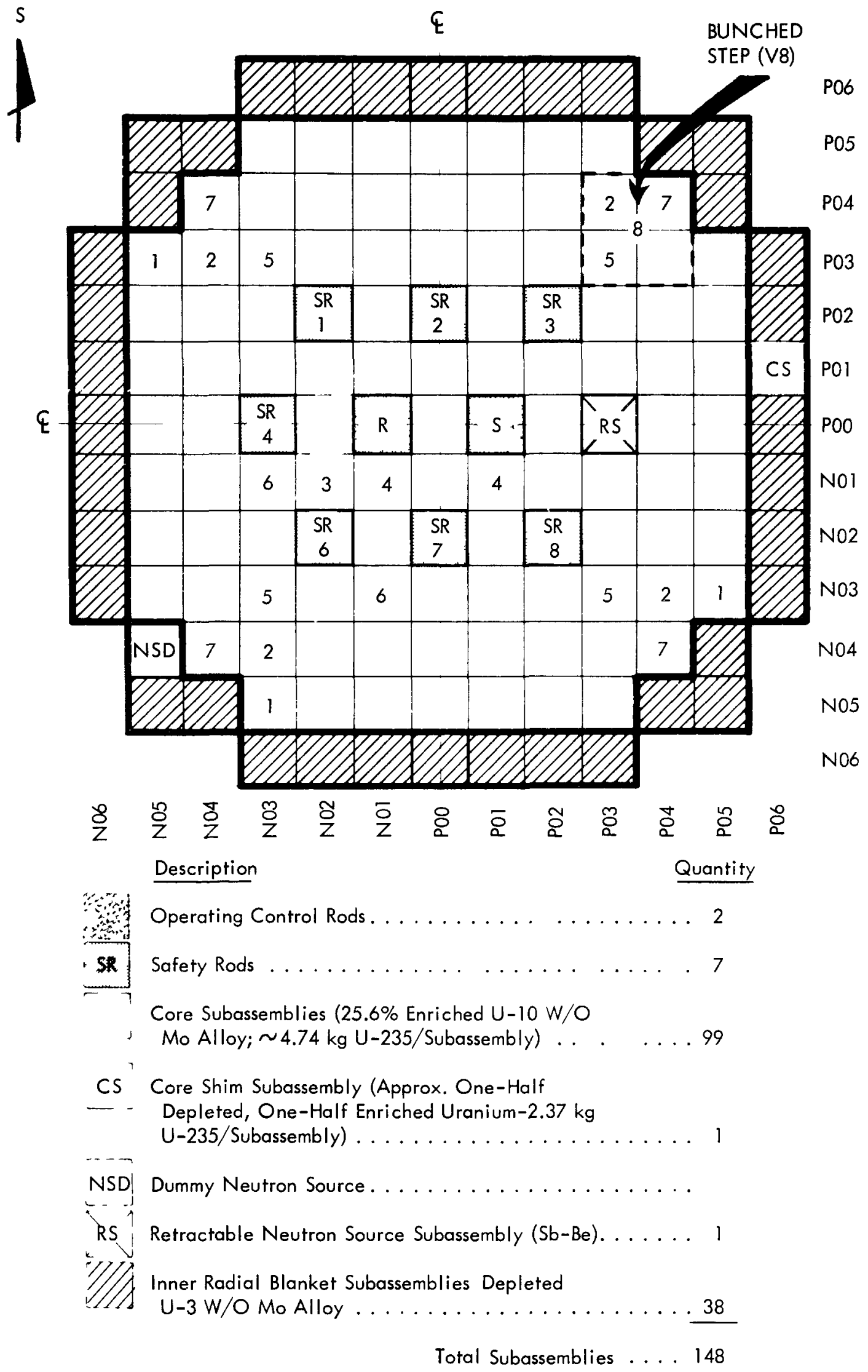

FIG. 4 CORE LOCATION INVOLVED IN SUBSTITUTIONS 
Reactor power levels were read from two source range counter channels equipped with RIDI 49-51 scalers, and from an ion chamber connected to a Keithly micromicroammeter linear recorder channel. Control rod positions were read from a Gilmore high-accuracy position readout as well as directly from the scale attached to each rod drive. System temperatures were maintained close to $517 \mathrm{~F}$ is othermal and monitored at frequent time intervals with high-precision, bridge-type readouts. Further details of the plant conditions and experimental equipment are given in Section III. C. below.

The several reactivity readings were made at each rod setting to reduce the over-all errors. A further important reduction in error was achieved by use of the one-period method. Positive-period (PP) measurements on certain steps, particularly the reference steps, were made with the regulating rod set close to the positions previously used during the PP and CRRP measurements on earlier steps. This was done in such a way that the later calculation of reactivity differences between the steps would not require absolute readings of the regulating rod calibration curve of reactivity versus rod position. Each such reading would introduce an error of approximately \pm 0.5 inhours*, amounting to an error of approximately \pm 0.7 inhour for each calculated step reactivity difference. Using the one-period method, only a small difference in the regulating rod position (0. 5 inch at most) appears in each calculation, and the corresponding reactivity correction can be made with an error of less than \pm 0.25 ih, knowing the slope of the regulating rod calibration curve to about $\pm \overline{5}$ per cent; the slope of the curve is $\lesssim 10$ ih per inch. These figures are an indication of the advantage of the technique used and are not, of course, sufficient for a full error analysis, which will be given later in this report.

\section{B. REACTOR PLANT CONDITIONS}

The reference reactor fuel loading (Figure 4) for the test consisted of 99 full-core subassemblies and one core-shim subassembly. With this loading, the excess reactivity was approximately 70 cents at the test temperature of $517 \mathrm{~F}$. The excess reactivity during the flooded loadings was essentially the same as that of the reference. In the case of the voided loadings, is was lower by 12 to 16 cents, depending on the positions at which the voided subassemblies were loaded. The reference excess reactivity value was chosen so that during the measurements the reactor could be made critical with the slow moving shim rod fully inserted and the regulating rod located in the middle third or linear portion of its travel. Thus the time required for making the measurements was kept to a minimum, and accurate reactivity analyses could be made using only the slope of the regulating rod calibration curve.

* For the Fermi Core A, the following regulations apply to the three commonly used reactivity units, assuming an effective delay fraction of 0.00662 :

$$
\begin{aligned}
& 1 \text { cent }=3.19 \text { inhours }\left(\text { ih); } 1 \text { ih }=2.08 \times 10^{-5} \Delta \mathrm{k} / \mathrm{k}\right. \\
& 1 \mathrm{ih}=2.08 \times 10^{-5} \Delta \mathrm{k} / \mathrm{k}
\end{aligned}
$$


The reactor power level was not allowed to exceed $10 \mathrm{kw}$ during the course of the test, and the total integrated power for any one run was kept below $1 \mathrm{kwhr}$. These restrictions were applied to prevent an exces sive temperature rise in the voided subassemblies when they were in the reactor and, also, to prevent excessive activation of the special subassemblies so that they could be handled safely after removal from the reactor. During the test, these were the only restrictions on reactor power. It was not necessary to use the same power level for all reactivity measurements because a retractable neutron source was available (Section III. C) and source reactivity effects were negligible at all power levels.

The temperature of the primary system was maintained as closely as possible at $517 \mathrm{~F}$ is othermal, the normal reactor refueling temperature. The reactor temperature was held steady at this value by maintaining a balance between the heat input, which resulted from primary sodium pump operation, and the heat removal from operation of the belowfloor ventilation system. The auxiliary cooling system, consisting of the overflow pumps and the primary system cold trap, was also operated when required to reduce the upward drift in temperature.

The nominal three-loop primary sodium flow rate maintained was the refueling value, $6.0 \times 10^{6} \mathrm{lb} / \mathrm{hr}$. To allow the test to be made at refueling flow, which is 68 percent of the Core $A, 200-M w t$ design flow, the low sodium flow scram setting of the reactor safety system was reduced from its normal setting of 75 percent to 40 percent of the Core A value. The intermediate range level scrams were set to scram the reactor at the flux level corresponding to $10 \mathrm{kw}$ and the power range level scrams were set at their minimum level which is approximately $1 \mathrm{Mw}$.

\section{NEUTRON SOURCE AND INSTRUMENTATION}

In place of safety rod No. 5, a temporary retractable neutron source was located in the reactor during the test. A precision temperature readout station was also located in the reactor control room to main tain an accurate record of reactor temperature. The positive period and power drift rate information were acquired using the data obtained from temporary neutron detectors installed for the low-power test program. The control rod positions were obtained from both the permanent plant instrumentation and from direct reading scales attached to the rod drives. The remaining test data, i. e., the primary sodium flow rates, safety rod positions, etc., were obtained from the permanent plant instrumentation.

\section{Neutron Source}

Throughout the sodium worth test, a temporary retractable antimony-beryllium ( $\mathrm{Sb}-\mathrm{Be}$ ) neutron source was located in the reactor in place of safety rod No. 5 in core position PO3-P00 (Figure 4). It took the 
place of the normal source located at the core-blanket interface (Figure 2). The temporary retractable source and its operation is described in Reference 2. The use of a retractable source permitted accurate reactivity measurements to be made at low power, thus minimizing the activation of core components and eliminating the need for applying source neutron reactivity corrections to be the measured data.

\section{Instrumentation}

Nuclear - The temporary neutron flux monitoring instrumentation used during the test was essentially the same as that described in detail in APDA-NTS-1. ${ }^{5}$ However, in this test no in-core instrumentation was used because the temporary instrument thimble, which was normally installed for the low-power tests in place of safety rod No. 5, had been replaced by the retractable source; consequently, all the neutron detectors were located outside of the core inside the detector guide tubes which penetrate the graphite shield that surrounds the reactor vessel (Figure 1).

Two high-sensitivity $\mathrm{BF}_{3}$ proportional detectors, connected to the source range instrumentation of the reactor safety system, were used to determine reactor periods. The count rate signals from the two $\mathrm{BF}_{3}$ detectors were relayed to two RIDI mechanical scalers located in the main control room that were switched with an Eagle Timer to count for 12 seconds every 15 seconds. The count rate data obtained from the scalers were then plotted on semilogarithmic graph paper to obtain the reactor periods. Period information was also obtained from the esponse of a B-10 lined ion chamber. The ion chamber provided a linear current signal to a Keithley micromicroammeter located in the reactor control room. The output of the micromicroammeter was connected to a recorder that had backset switches at 30 per cent and 81.5 per cent of full scale (an e-fold power increase). The switches operated a timer that gave a direct readout of the reactor period. The three periods obtained were averaged for use in the analysis. The micromicroammeter was also used to determine the neutron flux drift (power drift) during critical rod position reactivity measurements. From this data, reactivity corrections for power drift could be made. The data from the normal source range and intermediate range detectors in the plant were also recorded to provide a reference in the event that a failure occurred in the test instrumentation.

Temperature - The temperature of the primary system was monitored during the test by use of the normal plant temperature sensing elements; these sensing elements consist of iron-constantan thermocouples and platinum resistance temperature detectors. The thermocouples are installed on the fuel support plates located below the core and on the holddown plate located above the core. They measure the temperature of the core inlet and outlet sodium, respectively. The resistance temperature 
detectors are located in the primary sodium piping leading to and from the reactor and measure the temperature of the reactor inlet and outlet sodium. During the test, the signals from the temperature sensors were relayed via special circuits to the temporary precision temperature readout station located in the control room. The thermocouples were connected to a high-sensitivity potentiometer, and the resistance detectors were connected to a resistance bridge. With the equipment used, temperatures could be read to an accuracy of well below $\pm 1 \mathrm{~F}$.

Rod Position - The positions of the two operating control rods were determined from Gilmore digital position indicators and specially installed direct reading scales. The Gilmore indicators, located in the main control room, were connected to five-position potentiometers on the rod drives. The direct reading scales were located at the rod drives. The data from the direct reading scales were more accurate, and the scalewere used almost exclusively in the analysis of the test. The scales showed the elevation of the drive extensions to within \pm 0.03 inch (standard deviation).

Miscellaneous - The remaining instrumentation used to deter mine primary sodium flows, graphite shield temperatures, safety rod positions, gas pressures, and sodium levels was the normal plant equipment described in Reference 2 . 


\section{EXPERIMENTAL RESULTS AND ANALYSIS}

\section{A. REACTIVITIES MEASURED}

The results of the reactivity measurements made during the test with the shim rod fully inserted are presented in Table II.

\section{Measured Results}

The results in Table II were obtained in three stages, referred to as a step, measurement, or reading as defined below:

Step - A loading as defined previously in Section III. A. In Table II, steps are numbered in chronological order and by type, e.g., Reference (Rl), Voided (Vl), and Flooded (Fl).

Measurement - The average of a set of reactivity readings, either a set of PP or CRRP readings, determined for a given step and corresponding to a single regulating rod position for the step. Critical regulating rod position measurements are labeled a in Table II; positive-period measurements are labeled b, c, d, etc.

Reading - An individual PP or CRRP determination of excess reactivity. Several, usually 3 or 4 , were made and averaged to form a single measurement. Statistical independence of the readings was insured by disturbing the regulating rod after each reading and resetting it, neces sarily an imperfect setting, to the current measurement position for the next reading. The set of readings for each measurement was corrected to a single regulating rod position, a single reactor temperature of $518 \mathrm{~F}$ (assuming an is othermal temperature coefficient of 0.9 $\mathrm{ih} / \mathrm{F}$ ), and a zero power drift (CRRP results only). These results were averaged to give the single PP or CRRP measurement result.

\section{Probable Errors in Measurement}

The term probable error (PE) as used in this analysis refers to a condition of 50 per cent uncertainty, or approximately 0.7 times the standard deviation. The probable errors in Table II apply to the measurements, which are the average of several individual readings. The net probable errors that can be expected in single PP or CRRP readings are calculated from the following estimated errors. 
TABLE II -

\begin{tabular}{|c|c|c|c|c|c|c|c|c|c|c|c|c|}
\hline \multirow{2}{*}{\multicolumn{2}{|c|}{$\begin{array}{c}\text { Step No., } \\
\text { Chronological }\end{array}$}} & \multirow[b]{2}{*}{$\begin{array}{l}\text { Step No. } \\
\text { for } \\
\text { Analysis } \\
\end{array}$} & & \\
\hline & & & $\begin{array}{c}\text { Measure- } \\
\text { ment }\end{array}$ & $\begin{array}{l}\text { Regulat- } \\
\text { ing Rod } \\
\text { Position, } \\
\text { Inches }\end{array}$ & $\begin{array}{l}\text { Averaged } \\
\text { Excess } \\
\text { Reactivity, } \\
\text { Inhours }\end{array}$ & $\begin{array}{l}\text { Probable } \\
\text { Error } \\
\pm \text { Inhours } \\
\end{array}$ & $\begin{array}{l}\text { Number } \\
\quad \text { of } \\
\text { Readings } \\
\text { Averaged }\end{array}$ & $\begin{array}{c}\text { Measure- } \\
\text { ment }\end{array}$ & $\begin{array}{l}\text { Regulat- } \\
\text { ing Rod } \\
\text { Position, } \\
\text { Inches }\end{array}$ & $\begin{array}{c}\text { Averaged } \\
\text { Excess } \\
\text { Reactivity, } \\
\text { Inhours } \\
\end{array}$ & $\begin{array}{l}\text { Probable } \\
\text { Error, } \\
\pm \text { Inhours }\end{array}$ & 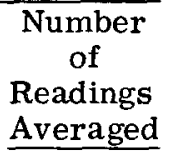 \\
\hline & 1 & $\mathrm{R} 1$ & $\mathrm{a}$ & 5.48 & 0.5 & 0.2 & 4 & b & 7.64 & 22.7 & 0.2 & 4 \\
\hline & 2 & $\mathrm{~V} 1$ & $a$ & 9.79 & -0.3 & 0.2 & 4 & b & 13.14 & 24.1 & 0.2 & 4 \\
\hline & 3 & $\mathrm{~V} 2$ & $\mathrm{a}$ & 10.42 & 0.6 & 0.2 & 4 & $\mathrm{~b}$ & 13.16 & 20.1 & 0.2 & 4 \\
\hline & 4 & V3 & $\mathrm{a}$ & 9.57 & -2.0 & 0.2 & 4 & $b$ & 13.21 & 24.5 & 0.2 & 4 \\
\hline & 5 & V4 & $\mathrm{a}$ & 9.19 & 1. 0 & 0.2 & 4 & $\mathrm{~b}$ & 13.20 & 30.4 & 0.2 & 4 \\
\hline & 6 & R2 & $\mathrm{a}$ & 5.30 & -0.1 & 0.2 & 3 & $\mathrm{~b}$ & 7.69 & 24.7 & 0.2 & 3 \\
\hline & 6 & R2 & & & & & & $\mathrm{c}$ & 9.61 & 42.7 & 0.4 & 1 \\
\hline & 6 & R2 & & & & & & $d$ & 10.16 & 47.5 & 0.4 & 1 \\
\hline & 6 & $\mathrm{R} 2$ & & & & & & e & 10.49 & 49.6 & 0.4 & 1 \\
\hline \multirow[t]{19}{*}{$\stackrel{N}{\sim}$} & 7 & V5 & $\mathrm{a}$ & 10.02 & 0.0 & 0.2 & 4 & $b$ & 13.27 & 23.3 & 0.2 & 4 \\
\hline & 8 & V6 & $\mathrm{a}$ & 9.75 & -1.0 & 0.2 & 4 & $\mathrm{~b}$ & 13.23 & 23.9 & 0.2 & 4 \\
\hline & 9 & V7 & $\mathrm{a}$ & 10.18 & -1.1 & 0.2 & 4 & $\mathrm{~b}$ & 13.20 & 20.7 & 0.2 & 4 \\
\hline & 10 & V8 & $\mathrm{a}$ & 10.30 & -1.3 & 0.2 & 4 & $\mathrm{~b}$ & 13.20 & 19.4 & 0.2 & 4 \\
\hline & 11 & $\mathrm{R} 3$ & $\mathrm{a}$ & 5. 44 & 1.2 & 0.2 & 3 & b & 7. 63 & 24.1 & 0.2 & 3 \\
\hline & 11 & $\mathrm{R} 3$ & & & & & & $c$ & 10.00 & 46.0 & 0.2 & 3 \\
\hline & 11 & R3 & & & & & & $\mathrm{d}$ & 9.50 & 41.8 & 0.2 & 3 \\
\hline & 11 & R3 & & & & & & $e$ & 9.10 & 38.3 & 0.3 & 2 \\
\hline & 11 & $\mathrm{R} 3$ & & & & & & f & 10.33 & 49.0 & 0.3 & 2 \\
\hline & 12 & $\mathrm{R} 4$ & $\mathrm{a}$ & 5.26 & -0.8 & 0.3 & 2 & b & 7.64 & 23.5 & 0.3 & 2 \\
\hline & 12 & $\mathrm{R} 4$ & & & & & & $c$ & 9.50 & 41.5 & 0.3 & 2 \\
\hline & 13 & F1 & $\mathrm{a}$ & 5.29 & -0.6 & 0.2 & 4 & $b$ & 9.78 & 43.7 & 0.2 & 4 \\
\hline & 13 & F1 & & & & & & $\mathrm{c}$ & 7.64 & 23.7 & 0.3 & 2 \\
\hline & 14 & F4 & $\mathrm{a}$ & 5.26 & -0.1 & 0.2 & 4 & b & 9.11 & 39.1 & 0.2 & 4 \\
\hline & 14 & F4 & & & & & & c & 7. 64 & 24.7 & 0.2 & 3 \\
\hline & 15 & F6 & $a$ & 5.56 & -0.6 & 0.2 & 4 & $\mathrm{~b}$ & 9.78 & 40.8 & 0.2 & 4 \\
\hline & 15 & F6 & & & & & & $\mathrm{c}$ & 7. 64 & 20.5 & 0.2 & 3 \\
\hline & 16 & R5 & $\mathrm{a}$ & 5.20 & -0.4 & 0.2 & 3 & $\mathrm{~b}$ & 7.64 & 24.7 & 0.2 & 3 \\
\hline & 16 & $\mathrm{R} 5$ & & & & & & $\mathrm{c}$ & 9.50 & 42.2 & 0.2 & 3 \\
\hline
\end{tabular}




\section{Source}

(a) Regulating Rod Position, from

Scale readings on rod drive

(b) Reactor Temperature

(c) Period Calculated from Power Plot, $P P$ readings only

(d) Correction to Zero Power Drift, CR $R$ P readings only

Net for a single PP Reading

Net for a single CRRP Reading
Estimated PE, inhours

\pm 0.02 in. $= \pm 0.2$

$\pm 0.2 \mathrm{~F}= \pm 0.2$

$\pm 0.3$

$\pm 0.1$

$+0.4$

$\pm 0.3$

The net probable exrors were obtained by taking the square root of the sum of the squares of items (a), (b), and (c) for a PP reading and of items (a), (b), and (d) for a CRRP reading. They are given to the nearest 0.1 inhour.

The net $P E$ in a measurement averaged from ( $n$ ) independent readings is approximately $\left(\mathrm{n}^{-1 / 2}\right)$ times the $\mathrm{PE}$ in a single reading; this result, to the nearest 0.1 inhour, appears in Table II.

\section{B. METHOD OF ANAIYSIS}

The method of analysis carefully attempted to preserve the relatively small differences in columnar sodium worth observed across the core radius. It also allowed an estimate to be made of the over-all accuracy of the experiment, accounting for the reactivity disturbances produced by reactor reloading in addition to the measurement inaccuracies. The approach is discussed in the following paragraphs; further details appear in Section IV. C.

\section{Preservation of Small Reactivity Differences}

As discussed in Section III. A. 3, the one-period method was used to preserve small reactivity differences throughout the analysis. This method only permits intercomparison to be made among those reactivities measured with closely similar regulating rod positions; however, subject to this condition, measurements of either PP- or CRRP-type may be mixed. (CRRP measurements can be regarded as PP determinations of infinite period.) This approach leads to an initial comparis on of voided steps to reference steps and flooded steps to reference steps, rather than direct comparis on of voided steps to flooded steps which may appear more natural for an evaluation of the sodium worth. 


\section{Interpolation for Missing Flooded Steps}

The lack of three of the seven basic flooded steps, explained in Section III. A. 2, is circumvented by estimating the four unknown comparisons of flooded steps versus the reference step. This requires an inter polation among the results of the three known comparisons, together with available data for calculating the reactivity effects due to U-235 mass differences when the flooded special subassemblies replace the normal core subassemblies.

\section{Estimate of Uncertainty in Reactivity after Reloading}

The five reference results were examined for evidence of any systematic reactivity drift with time; no significant amount was found. The spread of the five reference reactivities was thus attributed to the three random uncertainties known to affect such repeated results*, namely:

(a) Measurement errors, discussed in Section IV. A. 2.

(b) Variations in core tightness between operations of the holddown mechanism.

(c) Variable reorientation of any subassembly between its loading and reloading.

The latter items (b) and c), which need not be separated for present purposes, are of general significance apart from their appearance in this particular test. Together they represent a basic "reloading uncertainty" that cannot be eliminated from any test involving reactor reloadings between reactivity measurements. Theoretical estimates $6,7,8$ of the size of this uncertainty indicate a result of approximately 1 ih. The experimental evaluation shown in the data reduction of the reference steps is thus of considerable interest (a value of \pm 0.4 ih was obtained).

\section{DATA REDUCTION}

To apply the one-period method of reactivity comparis on used throughout, the slope of the regulating rod reactivity calibration curve 5 was tablulated against rod position in Table III.

* Using data from later nuclear tests, collected over much longer time periods, definite evidence of a systematic drift was found (+ 1 to 2 ih per month); hence, the present estimate of reloading uncertainty is conservatively large. 
TABLE III - SLOPE OF REGULATING ROD CALIBRATION CURVE

Regulating Rod Position, inches withdrawn

$13.2 \quad 10.5 \quad 10.0 \quad 9.5 \quad 9.0$

8.5

8.0 to 4.0

Reactivity Change Slope,

ih per inch withdrawn

6.5

8.59 .0

9.510 .0

10.5

Particular results for intermediate regulating rod positions at 0.1 inch intervals were obtained from Table III by linear interpolation.

\section{Reference Steps and Reloading Uncertainty}

The measurements for reference steps $\mathrm{R} 1$ through $\mathrm{R} 5$, Table II, were corrected to the nearest one of five regulating rod positions selected as suitable standards using Table III. Measurements lettered(a)were CRRP type; the remainder were PP type. The results appear in Table IV. In Table IV-A an intercomparis on was made among the five reference steps by taking reactivity differences at each rod position relative to the extensively measured Step R 2 and averaging these differences for each step. In Table IV $-B$, the same process is repeated independently relative to Step $R 3$. The two average distributions have essentially the same standard deviation, $\sigma^{2}=0.44$, and about the same mean reactivity (midway between $R 2$ and $R 3)$. The measurement $P E$ on each average result is \pm 0.2 ih.

As discussed in Section IV-B. 3 above, this observed standard deviation is attributed to the combined random effect of the measurement $\mathrm{PE}$ and the unknown "reloading uncertainty". The latter can then be evaluated as follows:

Let

$$
\begin{aligned}
& \sigma_{\mathrm{m}}=\text { standard deviation due to measurement errors } \\
& \sigma_{\mathbf{r}}=\text { standard deviation due to reloading uncertainty } \\
& \mathrm{P}_{\mathrm{m}}=\text { probable error due to measurement errors } \\
& P_{\mathbf{r}}=\text { probable error due to reloading uncertainty }
\end{aligned}
$$

Then

$$
\begin{aligned}
& \sigma^{2}=\sigma_{\mathrm{m}}^{2}+\sigma_{\mathrm{r}}^{2} \\
& \text { and } \mathrm{P}_{\mathrm{m}} \doteq 0.7 \sigma_{\mathrm{m}} \\
& \mathrm{P}_{\mathrm{r}} \doteq 0.7 \sigma_{\mathrm{r}}
\end{aligned}
$$

Therefore

$$
P_{r}=\sqrt{(0.7 \sigma)^{2}-P_{m}^{2}}
$$


TABLE IV - REFERENCE REACTIVITIES RELATIVE TO FIVE STANDARD REGULATING ROD POSITIONS

Standard

Regulating

Rod Posi-

\begin{tabular}{|c|c|c|c|c|c|}
\hline ion, in. & Step R 1 & Step R2 & Step R 3 & Step R4 & Step R5 \\
\hline 5.48 & $0.5 \pm .2$ & a. $1.8 \pm .2$ & a. $1.6 \pm .2$ & $1.5 \pm .3$ & a. $2.5 \pm .2$ \\
\hline 7.64 & b. $22.7 \pm .2$ & b. $24.2 \pm .2$ & b. $24.2 \pm .2$ & b. $23.5 \pm .3$ & b. $24.7 \pm .2$ \\
\hline 9.50 & - & c. $41.7 \pm .4$ & $\begin{array}{l}\mathrm{d}, \mathrm{e} \\
\operatorname{avg}\end{array} 41.9 \pm .2$ & c. $41.5 \pm .3$ & c. $42.2 \pm .3$ \\
\hline 10.16 & - & d. $47.5 \pm .4$ & c. $47.4 \pm .2$ & - & - \\
\hline 10.49 & - & e. $49.6 \pm .4$ & f. $50.3 \mp .3$ & - & - \\
\hline
\end{tabular}

Measurements lettered (a) are CRRP; the others are PP.

Errors are measurement PE.

TABLE IV-A - REFERENCE INTERCOMPARISON RELATIVE TO STEP R2 Standard

Regulating

Rod Posi-

tion, in.

5.48

7.64

9.50

10.16

10.49

Average

for Step

$-1.40 \pm .2$

$0 \pm .2$

$0.12 \pm .2$

$-0.40 \pm .2$

$0.57 \pm .2$

TABLE IV-B - REFERENCE INTERCOMPARISON RELATIVE TO STEP R3 Standard Regulating Rod Position, in.

\begin{tabular}{l} 
R1 vs R3 \\
$-1.1 \pm .3$ \\
$-1.5 \pm .3$ \\
- \\
- \\
\hline
\end{tabular}

R2 vs R3

R 3 vs R 3

R 4 vs R 3

R 5 vs $R 3$

5.48

7.64

$0.2 \pm .3$

$0 \mp .3$

$0+.3$

$0 \mp .3$

$-0.2 \pm .4$

$0 \pm .3$

$0.1 \pm .4$

$0 \pm .3$

$-0.7 \pm .5$

$0 \pm .4$

$-0.1 \pm .4$

$-0.7 \pm .4$

$0.9+.3$

9.50

10.49

Average

for Step

$$
-1.35 \pm .2 \quad-0.12 \pm .2
$$

$0 \pm .2$

$-0.40 \pm .2$

$0.57 \pm .2$ 
Using Equation (1) and the values $\sigma^{2}=0.44 \mathrm{ih}^{2}$ and $\mathrm{P}_{\mathrm{m}}= \pm 0.2 \mathrm{ih}$ from Tables IV - A and IV-B, the probable error in reactivity due to "reloading uncertainty" becomes

$$
P_{r}= \pm 0.4 \mathrm{ih}
$$

This error, $P_{r}$, should be applied to all analyses of Fermi reactor tests that involve reloading between reactivity measurements. It expresses the basic uncertainty in determining any reactivity state of the reactor over and above the effects of any measurement errors. In other words, the accuracy of any determination of the reactivity difference between two reactor conditions separated by a reloading operation is limited to a value of \pm 0.6 ih, regardless of the accuracy of the measurement. (The reactivity of each reactor step is uncertain to $\pm 0.4 \mathrm{ih}$; therefore, the reactivity difference is uncertain to $\pm \sqrt{2} \times 0.4 \mathrm{ih} \cong \pm 0.6 \mathrm{ih}$.)

\section{Voided Steps}

In Table $V$, the CRRP and $P P$ reactivity measurements on voided Steps Vl to V8 are independently compared to the corresponding measurements on reference Step R3; the two independent comparisons are then averaged. The probable error, $\pm 0.6 \mathrm{ih}$, due to the "reloading uncertainty" between the voided steps and reference step $\mathrm{R} 3$ is introduced into the averaged comparisons; errors appearing before this stage are measurement $\mathrm{PE}$ only.

The procedure used to obtain the data listed in Table $\mathrm{V}$ is dis cussed below. Note that certain columns in the table are designated $\mathrm{A}$ through $E$ and are thus referred to in the text.

(a) The CRRP voided measurements are compared directly with the reference step measurement and the reactivity differ ences listed in Column (A).

(b) Before a similar comparison is possible with the PP voided measurements, the conversion process which follows is necessary

Each PP measurement is corrected to a uniform regulating rod position of 13.20 inches, the values shown in Column (B).

Each result is then subtracted from the corresponding comparison in Column(A)to yield a value of the regulating rod worth between 13.20 inches and the critical position for reference step $R 3$. These values are listed in Column (C). 
TABLE V - VOIDED STEPS COMPARED TO REFERENCE STEP R3

Voided CRRP

\begin{tabular}{|c|c|c|}
\hline $\begin{array}{c}\text { Step and } \\
\text { Measurement } \\
\text { Number }\end{array}$ & $\begin{array}{c}\text { Regulating } \\
\text { Rod Position, } \\
\text { Inches }\end{array}$ & $\begin{array}{c}\text { Excess } \\
\text { Reactivity, } \\
\text { Inhours }\end{array}$ \\
\hline V1 a & 9.79 & $-0.3 \pm 0.2$ \\
\hline V2 a & 10.42 & $0.6 \pm 0.2$ \\
\hline V3 a & 9.57 & $-2.0 \pm 0.2$ \\
\hline V4 a & 9.19 & $1.0 \pm 0.2$ \\
\hline V5 a & 10.02 & $0.0 \pm 0.2$ \\
\hline V6 a & 9.75 & $-1.0 \pm 0.2$ \\
\hline V7 a & 10.18 & $-1.1 \pm 0.2$ \\
\hline V8 a & 10.30 & $-1.3_{-0.2}^{+}$ \\
\hline
\end{tabular}

Reference Step R3

\begin{tabular}{|c|c|c|c|c|}
\hline $\begin{array}{c}\text { Step and } \\
\text { Measurement } \\
\text { Number } \\
\end{array}$ & $\begin{array}{c}\text { Regulating } \\
\text { Rod Position, } \\
\text { Inches } \\
\end{array}$ & $\begin{array}{c}\text { Excess } \\
\text { Reactivity, } \\
\text { Inhours } \\
\end{array}$ & $\begin{array}{c}\text { Excess Reactivity } \\
\text { Corres. to CRRP } \\
\text { Regulating Rod } \\
\text { Position, Inhours } \\
\end{array}$ & $\begin{array}{c}\text { Comparison } \\
\text { (CRRP - R3) } \\
\text { Reactivity Inhours } \\
\text { Difference, } \\
\end{array}$ \\
\hline R3 d & 9.50 & $41.8 \pm 0.2$ & $44.3 \pm 0.2$ & $\begin{array}{c}\text { Column (A) } \\
-44.6 \pm 0.3\end{array}$ \\
\hline R3 f & 10.33 & $49.0 \pm 0.3$ & $49.7 \pm 0.3$ & $-49.1 \pm 0.4$ \\
\hline R3 d & 9.50 & $41.8 \pm 0.2$ & $42.4 \pm 0.2$ & $-44.4 \pm 0.3$ \\
\hline R3 e & 9.10 & $38.3 \pm 0.3$ & $39.1 \pm 0.3$ & $-38.1 \pm 0.4$ \\
\hline R3 c & 10.00 & $46.0 \pm 0.2$ & $46.2 \pm 0.2$ & $-46.2 \pm 0.3$ \\
\hline R3 d & 9.50 & $41.8 \pm 0.2$ & $43.9 \pm 0.2$ & $-44.9 \pm 0.3$ \\
\hline $\mathrm{R} 3 \mathrm{c}$ & 10.00 & $46.0 \pm 0.2$ & $47.5 \pm 0.2$ & $-48.6 \pm 0.3$ \\
\hline R3 f & 10.33 & $49.0_{-0.3}^{+0.3}$ & $48.8_{-0.3}^{+}$ & $-50.1 \pm 0.4$ \\
\hline
\end{tabular}

Voided PP

Excess Reactivity Reg. Rod Worth

Correcd. to Uniform Between 13.20 in.

13. 20-in. Regulating

and CRRP of Ref

Step R3, Inhours

Column (B) Column (C) $=(\mathrm{A})-(\mathrm{B})$
PP to Ref. R3

Reactivity, Inhours

Column (D) $=\operatorname{Avg}(\mathrm{C})$

$-69.0 \pm 0.1$

"

"'

11

i1

19
Conversion Factor for
Comparison

(PP - R3)

Reactivity

Difference, Inhours

Column $(E)=(B) \&(D)$

$-44.5 \pm 0.3$

$-48.6 \pm 0.3$

$-44.6 \pm 0.3$

$-38.6 \pm 0.3$

$-46.2 \pm 0.3$

$-45.4 \pm 0.3$

$-48.3 \pm 0.3$

$-49.6 \pm 0.3$
24. $5 \pm 0.2$

20. $4_{-}^{+} 0.2$

24. $4 \pm 0.2$

30. $4_{-0.2}^{+0}$

22. $8 \pm 0.2$

23. $6 \pm 0.2$

20. $7 \pm 0.2$

19. $4 \pm 0.2$

$-69.1 \pm 0.4$
$-69.5 \pm 0.4$
$-68.8 \pm 0.4$
$-68.5 \pm 0.4$
$-69.0 \pm 0.4$
$-68.5 \pm 0.4$
$-69.3 \pm 0.4$
$-69.5 \pm 0.4$

$-69.1 \pm 0.4$

$-69.5 \pm 0.4$

$30.4 \pm 0.2$

23. $9 \pm 0.2$

20. $7 \pm 0.2$

19. $4_{-0.2}^{+}$

\begin{tabular}{c} 
Average of Voided CRRP and Voided PP \\
\hline V1 \\
V2 \\
V3 \\
V4 \\
V5 \\
V6 \\
V7 \\
V8
\end{tabular}

* Including reloading uncertainty in errors (see text). 


$$
\text { Column }(B)-\operatorname{Column}(A)=\operatorname{Column}(\mathrm{C}) *
$$

The quantity in Column $\mathrm{C}$ is physically a constant; therefore, the average (Column D) of the individual step values (Column C) is treated as a conversion factor which, when added to the $P P$ results in Column $B$, yields the reactivity differences, Column (E), between the $P P$ voided meas urements and reference Step R3.

\section{Flooded Steps and Missing Flooded Steps}

In Table VI, the CRRP and PP reactivity measurements on the flooded Steps F1, F4, and F6 are compared with the corresponding CRRP and PP measurements on reference Step R3; all the comparisons for each flooded step are then averaged. The probable error, $\pm 0.6 \mathrm{ih}$, due to the "reloading uncertainty" between the flooded steps and reference Step R 3 is introduced into the averaged comparisons; errors appearing before this stage are measurement PE only.

The reactivities of the five missing flooded steps, numbered $F 2^{\prime}$ $F 3^{\prime}, F 5^{\prime}, F 7^{\prime}$, and $F 8^{\prime}$ to follow the correspondingly numbered voided step, are estimated relative to the reference Step $R 3$.

The reactivity difference $\delta R_{f}$ observed between each measured flooded step (reactivity $R_{f}$ ) and the reference step (reactivity $R_{r}$ ) is the sum of the two components:

$$
\delta R_{f} \equiv\left(R_{f}-R_{r}\right)=\delta R_{m}+\delta R_{b}
$$

The first component, $\delta R$, is due to mass differences of $U-235$ between the four special sodium subassemblies and the four normal core subas semblies which they replace for each flooded loading. The second com ponent, $\delta \mathrm{R}_{\mathrm{b}}$, is due to the differences in axial blanket design between special and normal subassemblies (lack of axial blanket pins and presence of upper - and lower-steel bulkheads in each special subassembly).

* Let $V(p), R(p)$ represent the excess reactivities of the voided PP and reference $\mathrm{R} 3$ loadings, respectively, with regulating rod position p. Let $v, r$ represent the voided $P P$ and reference $R 3$ critical regulating rod positions, respectively.

Then Column (A) $\equiv-R(v) \equiv V(r)$ Column $(B) \equiv V(13.2)$

$$
\therefore C \equiv B-A=[V(13.2)-V(r)]
$$

This quantity is the regulating rod worth between 13.20 inches and reference $R 3$ critical position, as stated in the text. 
TABLE VI - FLOODED STEPS F1, F4, F6 COMPARED WITH REFERENCE STEP R3

Flooded Steps

\begin{tabular}{|c|c|c|c|c|c|c|c|c|}
\hline \multicolumn{3}{|c|}{ Flooded Steps } & \multicolumn{4}{|c|}{ Reference step R3 } & \multicolumn{2}{|c|}{ Comparison } \\
\hline $\begin{array}{c}\text { Step } \\
\text { Measurement } \\
\text { Number } \\
\end{array}$ & $\begin{array}{c}\text { Regulating } \\
\text { Rod Position, } \\
\text { Inches } \\
\end{array}$ & $\begin{array}{c}\text { Excess } \\
\text { Reactivity, } \\
\text { Inhours } \\
\end{array}$ & $\begin{array}{c}\text { Step and } \\
\text { Measurement } \\
\text { Number } \\
\end{array}$ & $\begin{array}{c}\text { Regulating } \\
\text { Rod Position, } \\
\text { Inches } \\
\end{array}$ & $\begin{array}{c}\text { Excess } \\
\text { Reactivity, } \\
\text { Inhours } \\
\end{array}$ & $\begin{array}{c}\text { Excess Reactivity } \\
\text { Corrected to Flooded } \\
\text { Regulating Rod } \\
\text { Position, Inhours } \\
\end{array}$ & $\begin{array}{c}\text { (Flooded-R3) } \\
\text { Reactivity } \\
\text { Difference, } \\
\text { Inhours } \\
\end{array}$ & $\begin{array}{c}\text { Average, } \\
\text { Inhours } \\
\end{array}$ \\
\hline F1 a & 5.29 & $-0.6_{-0.2}^{+}$ & R3 a & 5. 44 & $1.2 \pm 0.2$ & $-0.4_{-0.2}^{+}$ & $-0.2 \pm 0.3$ & \\
\hline F1 b & 9.78 & $43.7^{+} 0.2$ & $\mathrm{R} 3 \mathrm{c}$ & 10.00 & $46.0^{+} 0.2$ & 44. $1 \pm 0.2$ & $-0.4^{ \pm} 0.3$ & $-0.4^{ \pm} 0.6$ \\
\hline F1 c & 7.64 & $23.7^{ \pm}-0.3$ & $\mathrm{R} 3 \mathrm{~b}$ & 7. 63 & $24.1_{-0.2}^{+}$ & $24.2_{-0.2}^{+}$ & $-0.5_{-}^{+} 0.4$ & \\
\hline F4 a & 5.26 & $-0.1_{-0.2}^{+} 0$ & R3 a & 5. 44 & $1.2 \pm 0.2$ & $-0.7_{-}^{+} 0.2$ & $0.6_{-0.3}^{+} 3$ & \\
\hline F4 b & 9.11 & $39.1 \pm 0.2$ & R3 e & 9.10 & $38.3 \pm 0.3$ & $38.4_{-0.3}^{+0}$ & $0.7 \pm 0.4$ & $0.6 \pm 0.6$ \\
\hline F4 c & 7.64 & $24.7 \pm 0.2$ & $\mathrm{R} 3 \mathrm{~b}$ & 7.63 & $24.1 \pm 0.2$ & $24.2^{+} 0.2$ & $0.5 \pm 0.3$ & \\
\hline F6 a & 5.56 & $-0.6_{-0.2}^{+0.2}$ & R3 a & 5.44 & $1.2 \pm 0.2$ & $2.5_{-0.2}^{+0}$ & $-3.1 \pm 0.3$ & \\
\hline F6 b & 9.78 & $40.8_{-0.2}^{+}$ & $\mathrm{R} 3 \mathrm{c}$ & 10.00 & $46.0 \pm 0.2$ & 44. $1_{-0}^{+} 0.2$ & $-3.3 \pm 0.3$ & $-3.4 \pm 0.6$ \\
\hline F6 c & 7.64 & $20.5 \pm 0.2$ & $\mathrm{R} 3 \mathrm{~b}$ & 7.63 & $24.1 \pm 0.2$ & $24.2^{+} 0.2$ & $-3.7_{-0.3}^{+}$ & \\
\hline
\end{tabular}

\footnotetext{
* Including "reloading uncertainty" in errors (See text).
} 
The reactivity difference $\delta \mathrm{R}_{\mathrm{V}}$ between each voided step and the reference step is the sum of three components:

$$
\delta R_{v}=\left(R_{v}-R_{r}\right)=\delta R_{m}+\delta R_{b}-\delta R_{s}
$$

The first two components are the same as in Equation (2) (neglecting any possible variations due to the different sodium contents) and the third component, $\delta R_{s}$, is the desired worth of sodium removed from the four voided special $\stackrel{S}{S}$ ubassemblies. Equations (2) and (3) show that, as expected, a simple subtraction of $\delta \mathrm{R}$ from $\delta \mathrm{R}_{\mathrm{f}}$ suffices for the sodium worth evaluation; however, before this can be made in the case of missing flooded steps, the missing values of $\delta R_{f}$ must be estimated. This is done as illus trated in Table VII: $\delta \mathrm{R}_{\mathrm{m}}$ is calculated for all steps using the subassembly manufacturer's U-235 assay data ${ }^{9}$ and Fermi Core A measurement of U-235 worth. 10 Then $\delta R_{b}$ is calculated for the measured flooded steps as $\delta R_{f}-\delta R_{m}$, and $\delta R_{b}$ is estimated for the missing flooded steps $F 2^{\prime}$, etc., using a linear interpolation by radius. Adding back $\delta R$ for the missing steps, one obtains the missing values of $\delta \mathrm{R}_{\mathrm{f}}$. The uncertainties involved in this procedure, particularly when interpolating for the missing $\delta R_{b}$, are the largest sources of error in the test and can only be estimated roughly.* The fairly large differences among the three measured values of $\delta R_{b}$, which cause the large uncertainties in the interpolation, are thought to be due to perturbing effects of the control rods and safety rods near the measured subas sembly locations.

\section{Determination of Sodium Worth}

In Table VIII the voided reactivity relative to the reference $\delta R_{V}$ is subtracted from the flooded reactivity relative to the reference $\delta R_{f}$ to yield the worth of sodium present in each set of four core subassemblies.

\section{Effect of Bunching Voided Subassemblies}

To investigate possible reactivity effects from bunching, the voided subassemblies, the bunched result (Step 8 ) is compared with the corresponding unbunched average result, e.g., 1/2 Step $2+1 / 4$ Step $5+$ $1 / 4$ Step 7. The two values are $2.11 \pm 0.06$ cents per kilogram, respectively. It is concluded that no significant bunching effect has been observed within the experimental errors.

* Interpolation errors are estimated as \pm 1.5 ih for steps $F 3^{\prime}, F 5^{\prime}$; \pm 1.0 ih for steps F2', F8'; and \pm 0.5 ih for Step F7'. The \pm 0.6 ih measurement errors are then combined with these errors to give the total errors. All errors are probable errors. 


\section{TABLE VII - ESTIMATED MISSING FLOODED STEPS COMPARED WITH REFERENCESTEP R3}

\begin{tabular}{|c|c|c|c|c|c|c|c|c|}
\hline Step No & $\begin{array}{c}\text { Radius, } \\
\mathrm{cm}\end{array}$ & $\begin{array}{l}\text { Axial Core Ave } \\
\text { U-235 Lodding } \\
\text { Difference of } \\
\text { Step Compared } \\
\text { to Reference, kg }\end{array}$ & $\begin{array}{c}\text { U-235 Worth } \\
\text { at Step } \\
\text { Position, } \\
1 \mathrm{~h} / \mathrm{kg} \\
\end{array}$ & $\begin{array}{c}\delta \mathrm{R}_{\mathrm{m}} \\
\mathrm{hh} \\
\end{array}$ & $\begin{array}{c}\delta R_{f} \\
\text { Measured, } \\
\quad 1 h \\
\end{array}$ & $\begin{array}{c}\delta \mathrm{R}_{\mathrm{b}} \\
\equiv\left(\begin{array}{ll}\delta \mathrm{R}_{\mathrm{f}}-\delta \mathrm{R}_{\mathrm{m}}\end{array}\right), \\
\end{array}$ & $\begin{array}{c}\delta \mathrm{R}_{\mathrm{b}} \\
\begin{array}{c}\text { Interpolated } \\
\mathrm{ih}\end{array} \\
\end{array}$ & $\begin{array}{r}\quad \text { Missing } \delta R_{f} \\
\equiv\left(\delta R_{b}+\delta R_{m}\right), \\
1 h\end{array}$ \\
\hline F 1 & 39.9 & -0.012 & 20 & -0.2 & $-0.4 \pm 0.6$ & $-0.2 \pm 0.6$ & & \\
\hline $\mathrm{F} 2^{\prime}$ & 34.2 & -0.001 & 30 & -0.03 & & & $-1.4 \pm 1.2$ & $-1.4 \pm 1.2$ \\
\hline F3' & 15.3 & +0.003 & 65 & +0.2 & & & $-1.7 \pm 1.6$ & $-1.5 \pm 1.6$ \\
\hline $\mathrm{F} 4$ & 9.7 & +0.004 & 70 & +0.3 & $0.6 \pm 0.6$ & $0.3 \pm 0.6$ & & \\
\hline F $5^{\prime}$ & 29.1 & -0.059 & 40 & -2.4 & & & $-2.4 \pm 1.6$ & $-4.8 \pm 1.6$ \\
\hline F6 & 21.6 & +0.013 & 55 & +0.7 & $-3.4 \pm 0.6$ & $-4.1 \pm 0.6$ & & \\
\hline F.' & 38.7 & -0.059 & 25 & -1.5 & & & $-0.4 \pm 0.8$ & $-1.9 \pm 0.8$ \\
\hline F8' & 33.9 & -0.097 & 30 & -2.9 & & & $-1.4 \pm 1.2$ & $-4.3 \pm 1.2$ \\
\hline
\end{tabular}

\footnotetext{
See footnote on Page 30 concerning the errors in this colunn
} 
TABLE VIII - DETERMINATION OF SODIUM WORTH

Reactivity Differences Compared to Reference Step R3

\begin{tabular}{|c|c|c|c|}
\hline Step No. & $\mathrm{s}_{\mathrm{f}}$, ih & Step No. & $\frac{\delta \mathrm{R}_{\mathrm{v}}, \text { ih }}{}$ \\
\hline F1 & $-0.4 \pm 0.6$ & Vl & $-44.6 \pm 0.6$ \\
\hline $\mathrm{F}^{\prime}$ & $-1.4 \pm 1.2$ & $\mathrm{~V} 2$ & $-48.9 \pm 0.7$ \\
\hline F3' & $-1.5 \pm 1.6$ & V3 & $-44.5 \pm 0.6$ \\
\hline F4 & $0.6 \pm 0.6$ & V4 & $-38.3 \pm 0.7$ \\
\hline F5' & $-4.8 \pm 1.6$ & V5 & $-46.2 \pm 0.6$ \\
\hline F6 & $-3.4 \pm 0.6$ & V6 & $-45.2 \pm 0.6$ \\
\hline F7' & $-1.9 \pm 0.8$ & V7 & $-48.5 \pm 0.6$ \\
\hline F8' & $-4.3 \pm 1.2$ & V8 & $-49.9 \pm 0.7$ \\
\hline
\end{tabular}

Flooded Minus Voided = Sodium Worth

\begin{tabular}{|c|c|}
\hline $\begin{array}{c}\text { Sodium Worth in } \\
\text { Four Subassemblies } \\
\delta R_{f}-\delta R \text {, ih } \\
\end{array}$ & $\begin{array}{l}\text { Sodium Worth, } \\
\text { cents per kg* }\end{array}$ \\
\hline $44.2 \pm 0.8$ & $2.05 \pm 0.04$ \\
\hline $47.5 \pm 1.4$ & $2.20 \pm 0.06$ \\
\hline $43.0 \pm 1.7$ & $1.99 \pm 0.08$ \\
\hline $38.9 \pm 0.9$ & $1.80 \pm 0.04$ \\
\hline $41.4 \pm 1.7$ & $1.92 \pm 0.08$ \\
\hline $41.8 \pm 0.8$ & $1.94 \pm 0.04$ \\
\hline $46.6 \pm 1.0$ & $2.16 \pm 0.05$ \\
\hline $45.6 \pm 1.4$ & $2.11 \pm 0.06$ \\
\hline
\end{tabular}

* To obtain the sodium worth in cents per kilogram, the figures of 6.76 kilograms of sodium in four subassemblies and 3.19 inhours per cent have been used. 


\section{SODIUM WOR TH PREDICTIONS}

Two separate predictions were made from the results of this test: one was based on ZPR-III critical experiment measurements, and the other on multigroup diffusion calculations.

\section{A. ZPR - III PREDICTION}

Data from the ZPR-III mockup ${ }^{1}$ of Fermi Core A were used to make the sodium worth predictions 4,11 listed in Table IX. However, four aspects of the critical experiment made it difficult to accurately predict the sodium worth as discussed in the following paragraphs.

1. The worth of sodium could be measured in the critical experiment only for sodium insertions from zero to one-half of the full core sodium density due to insufficient sodium. Therefore, an extrapolation of the results was required to obtain the incremental sodium worth at full sodium density, believed to correspond to the Fermi experimental situation, which was an uncertain procedure. In the light of more recent work ${ }^{12}$, it appears that the assumed reduction of sodium worth with increased core sodium density was too strong, leading to predicted incremental worths lower than those observed.

2. The coolant in the experiment, not represented by sodium, was made up by reduced-density aluminum. This could have affected the observed trend of the reactivity measurements between zero and one-half of the full core sodium density, upon which the extrapolation to full core sodium density was based. Furthermore, the extrapolation required a correction for the worth of aluminum which was also an uncertain procedure.

3. Only the spatially averaged core sodium worth was measured in the critical experiment and not the worth distribution over the core, also needed for the prediction. The measured aluminum spatial worth distribution had to be assumed to apply to sodium, which could have led to an error in the prediction.

4. The core of the ZPR-III assembly was smaller then the final Fermi Core A design which would also lead to an error in the prediction.

The combined effect of these uncertainties led to an underestimation of the observed sodium worth distribution by about 20 per cent near the core edge and by over 100 per cent near the center. From a safety viewpoint, this was an error in a conservative direction. It should be added that the core average sodium worth observed in the ZPR-III experiment ${ }^{1}$, over the density range measured (from zero to one-half the full core sodium 


\section{TABLE IX - ZPR-III SODIUM WORTH PREDICTION}

\begin{tabular}{|c|c|c|c|}
\hline \multirow{2}{*}{$\begin{array}{c}\text { Flooded or } \\
\text { Voided Step No. }\end{array}$} & \multicolumn{2}{|c|}{ Core Radius, } & \multirow{2}{*}{$\begin{array}{l}\text { Measured Reactivity } \\
\text { Effect of Sodium Loss } \\
\text { From } 4 \text { SA, } \\
\text { Nearest Inhour }\end{array}$} \\
\hline & $\mathrm{cm}$ & in. & \\
\hline 1 & 39.9 & 15.7 & -44 \\
\hline 2 & 34.2 & 13.5 & -48 \\
\hline 3 & 15.3 & 6.0 & -43 \\
\hline 4 & 9.7 & 3.8 & -39 \\
\hline 5 & 29.1 & 11.4 & -41 \\
\hline 6 & 21.6 & 8.5 & -42 \\
\hline 7 & 38.7 & 15.3 & -47 \\
\hline 8 & \multicolumn{2}{|c|}{ (bunch) } & - \\
\hline
\end{tabular}

Sodium Worth Prediction 11 Using Corrected ZPR-III Results

Nearest Inhours

Inhours per $\mathrm{kg}$

$-33$

$-4.9$

$-39$

$-5.8$

$-18$

$-2.7$

$-13$

$-2.0$

$-35$

$-5.1$

$-25$

$-3.6$

$-36$

$-5.3$ 
density) prior to corrections to obtain the incremental worth, was 2.07 cents per kilogram--very close to the Fermi result. However, this "agreement" requires qualification: the ZPR-III figure represents a worth of 180 cents for 86.8 kilograms of sodium loaded with aluminum present also. * The Fermi result of 2.01 cents per kilogram represents a worth of 13.6 cents for a local sodium increment of 6.75 kilograms added in an "averaged core position" to an otherwise sodium-filled core.

\section{B. MULTIGROUP DIFFUSION THEORY PREDICTION}

To make the multigroup calculations ${ }^{13}$, a one- and two-dimensional diffusion theory code, CRAM ${ }^{14}$, a fixed microscopic cross-section library ${ }^{15}$, and first order perturbation theory were the basis. The library had 24 energy groups and had been developed for general sodium and Doppler coefficient calculations and not for the Fermi reactor in particular. The spectra from preliminary 24-group, one-dimensional calculations were used to generate 8-group cross sections for corresponding two-dimensional calculations. Two two-dimensional calculations were made: the first described a finite cylindrical (RZ) model of the whole reactor, approximating the sodiumfilled central and safety channels by two concentric annuli, and the core and blankets as perfect cylinders. The second calculation was in rectangular (XY) geometry representing the reactor midplane accurately as a lattice of square core, control, and blanket subassemblies. Axial buckling factors were calculated from the (RZ) results for each energy group at all important radii in the core midplane and incorporated into the (XY) calculation. This assured correct matching (XY) and (RZ) midplane fluxes--an important procedure in any calculation of a spectrum-sensitive quantity such as sodium worth by a method involving spatial synthesis.

Real and adjoint 8-group fluxes were computed for both models and multigroup perturbation calculations yielded the sodium worth as a function of position. The results are shown plotted in Figure 5. The (RZ) values are directly calculated axial core averages at typical radii from the (RZ) cylindrical calculation; each (XY) value is the product of the midplane worth from the (XY) calculation integrated over each subassembly position of experimental interest times the ratio of axial-to-midplane worth at the corresponding radius from the (RZ) calculation. The (XY) worths were normalized so that the leakage, absorption, and moderation components were each consistent with the corresponding component of the (RZ) midplane worths.

* An average sodium worth for a full 166 kilograms sodium core loading displacing all the aluminum was estimated as about 1.9 cents per kilogram by extrapolation of the partial-density measurements to full sodium density. 


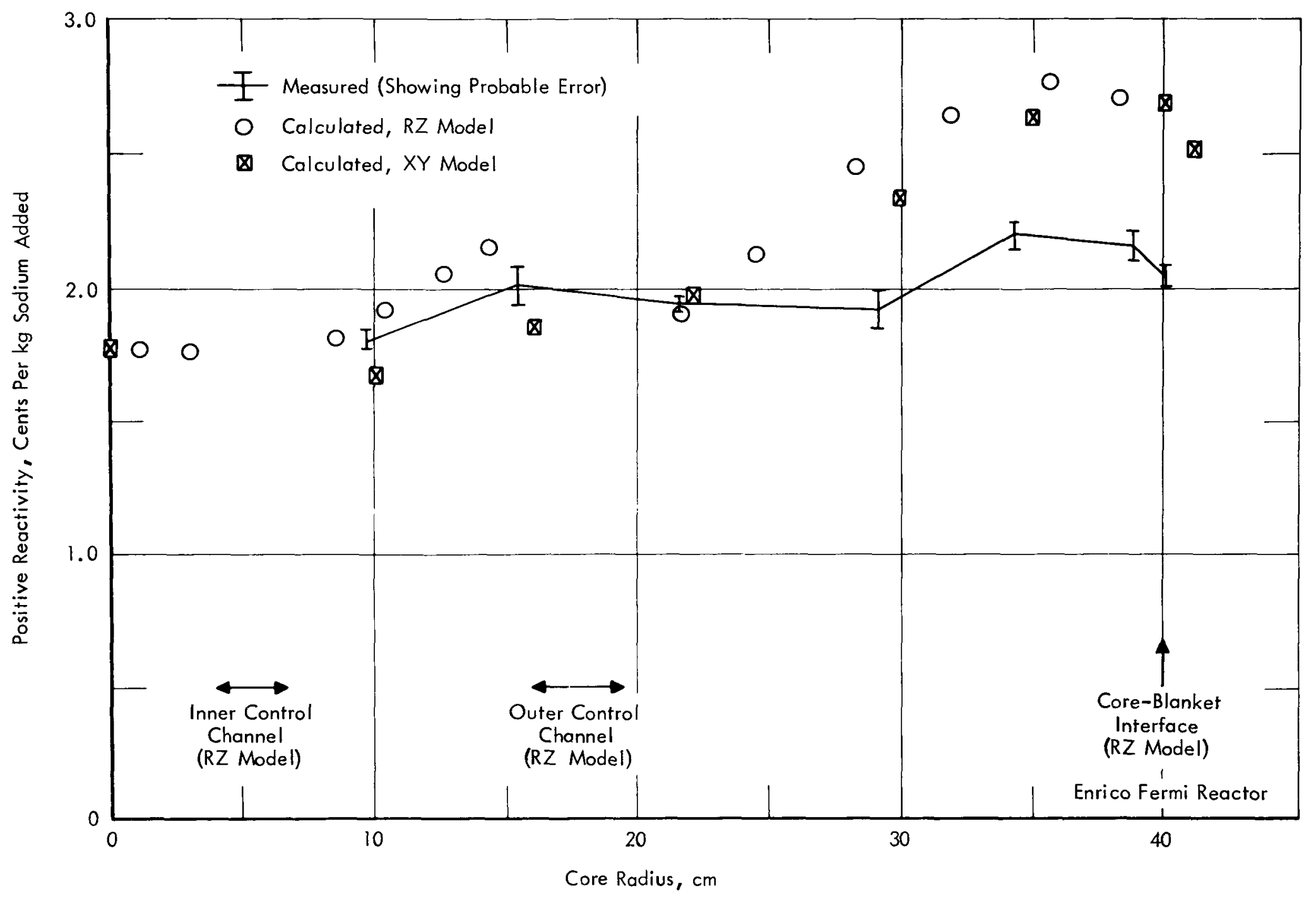

FIG. 5 MEASURED AND CALCULATED SODIUM WORTH 
Considering the straightforwardness of the methods used, agreement of the predicted values ${ }^{13}$ with the experimental results was good: for subassemblies near the center of the core the discrepancy was very small and closer to the core edge the prediction was about 25 per cent higher than the experimental results. Later work 12,16 has attempted to explain this discrepancy which at the time of this writing appears to be principally due to the uncertainty in the cross-section data of sodium and to uncertainty in the value assumed for the effective delayed-neutron fraction. * The latter affects the inhour relationship between the respective reactivity scales used for calculations and measurement: a value 10 per cent lower than that used in the present analysis is thought to be more reliable 17 which alone would lower all calculated values in Figure 5 by 10 per cent, improving the agreement considerably near the core edge.

$\bar{*} \beta_{\text {eff }}$ was assumed to be 0.00667 for the present calculations. 


\section{CONCLUSIONS}

A summary of the measured results, representing the worth of an axial column of sodium inserted into isolated, unfilled core subassemblies in an otherwise sodium-filled core is

$$
\begin{aligned}
& \text { Minimum, near core center }=+1.82 \text { cents per kilogram } \\
& \text { Maximum, near core edge }=+2.19 \text { cents per kilogram } \\
& \text { Average, averaged over core }=+2.01 \text { cents per kilogram }
\end{aligned}
$$

The existence of negative sodium temperature and void coefficients of reactivity is thus confirmed. All results have probable errors of less than \pm 5 per cent. The bunching effect, i. e., the reactivity change due to bunching together the four voided special subassemblies, was found to insignificant (within the experimental accuracy) relative to the result for the four separately located voided subassemblies.

The predicted experimental results were of more than adequate accuracy from a safety viewpoint and the measured results will provide a valuable target for present and future calculations. 


\section{REFERENCES}

1. C. E. Branyan, "Core A Critical Studies for the Enrico Fermi Atomic Power Plant on ZPR-III," ANL-6629, 1962.

2. PRDC, "Enrico Fermi Hazards Summary Report and Technical Information," Volumes 1-7, As Revised March 1964.

3. R. C. Williams, "Sodium Worth Subassemblies Void Volume Measurements," APDA Interna1 Memorandum, FAM-62-45, February 1962.

4. R. E. Horne, "Enrico Fermi Nuclear Test Procedure No. 18, Sodium Worth Measurements," APDA, 1962.

5. R. E. Mueller, C. E. Branyan, and J. B. Nims, "Initial Loading to Criticality of the Enrico Fermi Reactor," APDA-NTS-1, May 1964.

6. B. M. Segal, "Analysis of Errors in Nuclear Test Procedures Due to Fuel Subassembly Substitution with Uncertain Reorientation, " APDA Internal Memorandum, P-62-235, July 1962.

7. B. M. Segal, "Calculations for Three Specific Nuclear Test Procedures of Errors due to Uncertain Reorientation of Fuel Subassemblies, "APDA Internal Memorandum, P-62-250, August 1962.

8. B. M. Segal, "Error Analysis for Enrico Fermi Nuclear Test Procedure No. $16 b$ Reactivity Worth of Fuel Subassemblies in the IRB Positions," APDA, 1962.

9. Z. B. Dios, "Accountability of Enriched Subassemblies (Core Type A) at Fermi," PRDC Internal Memorandum, March 19, 1963.

10. G. L. Ba11, et al., "Worth Measurements of Core and Blanket Subassembly Materials in the Enrico Fermi Reactor," APDA-NTS-6, September 1965.

11. G. L. Ball, "Prediction of Results for Sodium Worth Experiments in Nuclear Test Procedure No. 18," APDA Internal Memorandum, P-62-296, August 1962 .

12. B. M. Segal, "Improved Calculations of Sodium Worth in the Enrico Fermi Fast Reactor," Trans. ANS, Vol. 7, No. 2, p. 240, 1964.

13. B. M. Segal, R. E. Horne, E. L. Alexanderson, "Sodium-Worth Measurements and Calculations on the Enrico Fermi Fast Reactor, "Trans. ANS, Vol. 7, No. 1, p. 174, 1964. 
14. A. Hassitt, "A Computer Program to Solve the Multigroup Diffusion Equations," TRG Report 229 (R), 1962.

15. J. J. Edwards, et al., "Fast Reactor Fuel Cycle Costs and Temperature Coefficients of Reactivity for $\mathrm{PuO}_{2}-\mathrm{SS}$ and $\mathrm{PuO}_{2}-\mathrm{UO}_{2}$," APDA-154, p. 35, 1963.

16. B. M. Segal, "Interim Summary of Work on Core A Sodium Worth," APDA Internal Memorandum, P-64-573, September 1964.

17. A. E. Klickman, Private Communication, 1965. 